\title{
Screen-printed Enzyme Electrodes Using Microcapsules Containing Glucose Oxidase and Mediator
}

\author{
Isao Shitanda, ${ }^{\text {* }}$ Masamitsu Kony a, ${ }^{\mathrm{a}}$ Masayuki Itagaki, ${ }^{\mathrm{a}}$ Kunihiro Watanabe, ${ }^{\mathrm{a}}$ and \\ Yasufumi ASANO ${ }^{\mathrm{b}}$
}

\author{
aDepartment of Pure and Applied Chemistry, Faculty of Science and Technology, Tokyo University of Science \\ (Noda, Chiba 278-8510, Japan) \\ bR\&D Section, Newlong Seimitsu Kogyo Co., Ltd. (Higashi-gotanda, Shinagawa-ku, Tokyo 141-0022, Japan)
}

Received February 29, 2008 ; Accepted June 21, 2008

\begin{abstract}
Polyamide microcapsule containing glucose oxidase (GOD) and tetrathiafulvalene (TTF) was prepared for the application to a molecular recognition element of screen-printed enzyme electrode. The microcapsules were entrapped in a polyion complex film or a carbon ink containing TTF, and then immobilized directly on the screenprinted carbon electrodes. The enzyme activity of the microcapsule was evaluated by the cyclic voltammetry in a phosphate buffer solution containing glucose. The enzyme electrodes were active to oxidize the dissolved glucose which is catalyzed by the entrapped GOD. In addition, the electroactive TTF molecules were proved to penetrate the polyamide membrane and to function as a mediator.
\end{abstract}

Key Words : Microcapsule, Screen-printing, Glucose Oxidase, Enzyme Electrode

\section{Introduction}

Screen-printing technique has been widely applied to the fabrication of enzyme electrodes ${ }^{1-7)}$ because it has the following merits: (a) drawing precise pattern of $\mu \mathrm{m}$ order, (b) a wide variety of inks, (c) high reproducibility, and (d) low cost. The screen-printed enzyme electrodes consist of several layers which were formed by depositing the inks successively. Enzyme inks have been prepared by mixing several components such as enzymes, conducting particles, solvents, mediators, catalysts, stabilizers and polymers in order to reduce number of manufacturing processes. Wang et al. ${ }^{1)}$ fabricated a disposable enzyme electrode used for a carbon ink containing cupric hexacyanoferrate and glucose oxidase. Hart et al. ${ }^{2}$ reported that an enzyme electrode modified with a graphite ink containing cholinesterase and cobalt phthalocyanine could be applied to the analysis of organophosphate pesticides. However, available enzymes applying to the enzyme ink are limited since these enzymatic activities are often inhibited by the other ink components.

We newly prepared an enzyme and mediator-containing microcapsule for the enzyme ink. The microencapsulation technique has been studied to protect the enzymatic activity from inhibitors and to improve long stability of the enzyme. ${ }^{8,9)}$ However, a enzyme-containing microcapsule has not been yet applied to electrochemical enzyme electrode fabricated by screen-printing.

In the present study, a polyamide microcapsule containing glucose oxidase (GOD) and tetrathiafulvalene (TTF) (GOD/TTF microcapsule) was prepared. The GOD/TTF microcapsule was entrapped in a polyion complex film and immobilized directly on the screenprinted carbon electrode. The enzymatic activities were measured by the cyclic voltammetry in order to evaluate availability of the enzyme-containing microcapsule as a molecular recognition element. In addition, a carbon ink containing TTF and the GOD/TTF microcapsules (microcapsule enzyme ink) was prepared. The microcapsule enzyme ink was printed on the carbon electrode by using the screen-printing technique, and the electrochemical performance was evaluated.

\section{Experimental}

Glucose oxidase (GOD) (EC 1.1.3.4, from Aspergillus sp., $345 \mathrm{U} \mathrm{mg}^{-1}$ ) and tetrathiafulvalene (TTF) were used as an enzyme and a mediator, respectively. The GOD and TTF-containing polyamide microcapsule (GOD/TTF microcapsule) was prepared by the interfacial polymerization method. ${ }^{8)}$ Cyclohexane, chloroform, terephthaloyl dichloride (TDC, Tokyo Kasei Kogyo), diethylenetriamine (DETA, Tokyo Kasei Kogyo), and sorbitanmonolaurate (Span 20, Wako) were used without further purification. Figure 1 shows the schematic illustration of the experimental set-up for the GOD/TTF microcapsule preparation. The organic solvent was $100 \mathrm{~cm}^{3}$ cyclohexane-chloroform mixed solvent $\left(50 \mathrm{~cm}^{3}\right.$ each) containing $2 \mathrm{wt} \%$ Span 20. A $67 \mathrm{~mol} \mathrm{dm}^{-3}$ phosphate buffer solution (PBS, $\mathrm{pH}=7.4,20 \mathrm{~cm}^{3}$ ) containing $2.3 \mathrm{mg} \mathrm{cm}^{-3}$ GOD, $0.5 \mathrm{~mol}$ $\mathrm{dm}^{-3}$ DETA and $1.0 \mathrm{~mol} \mathrm{dm}^{-3}$ sodium carbonate was mixed with a saturated TTF methanol solution $\left(5 \mathrm{~cm}^{3}\right)$ and then added in the organic solvent (Fig. 1(a)). The mixed solution was cooled to $4{ }^{\circ} \mathrm{C}$ and then mechanically agitated by a homogenizer (Ika Works, T18 Basic S2) at $10000 \mathrm{rpm}$ for $15 \mathrm{~min}$ in order to prepare water in oil (W/O) emulsion (Fig. 1(b)). A $100 \mathrm{~cm}^{3}$ cyclohexane-chloroform mixed solvent containing $55 \mathrm{mmol} \mathrm{dm}^{-3} \mathrm{TDC}$ was poured in the water in oil emulsion (Fig. 1(c)). This solu- 
tion was stirred by using a chemical stirrer (Shintoukagaku, JBL1200) at $800 \mathrm{rpm}$ for $30 \mathrm{~min}$ (Fig. 1(d)). The prepared GOD/TTF microcapsule was centrifuged and rinsed by ultrapure water. The GOD/TTF microcapsule was dispersed in a $40 \mathrm{~cm}^{3}$ phosphate buffer solution.

The GOD/TTF microcapsules were entrapped in a poly ion complex film coated on a homemade screenprinted carbon disk electrode surface $(\phi=5 \mathrm{~mm})$. The screen-printed carbon electrode was rinsed with sonicated water for 1 min prior to immobilizing the microcapsule. Poly(L-lysine) (PLL) (Aldrich, $M_{\mathrm{w}}=100,000$ ) as a polycation and poly(styrenesulfonate) (PSS) (Aldrich, $\left.M_{\mathrm{w}}=70,000\right)$ as a polyanion was used for preparation of the polyion complex film. PLL (25 $\mathrm{mM}$ in monomer unit, $0.01 \mathrm{~cm}^{3}$ ), PSS $\left(25 \mathrm{mM}\right.$ in monomer unit, $\left.0.01 \mathrm{~cm}^{3}\right)$, and the microcapsules $\left(0.01 \mathrm{~cm}^{3}\right)$ were successively cast on the electrode surface, followed by additional dropping of PLL $\left(0.01 \mathrm{~cm}^{3}\right)$ and PSS $\left(0.01 \mathrm{~cm}^{3}\right)$. The electrode was then dried for 1 hour at room temperature. Theoretical amount of GOD immobilized on the electrode surface was $8 \mathrm{U}$. The theoretical value was calculated by the assumption that all of GOD was entrapped in the polyamide microcapsule at the interfacial polymerization reaction. On the other hand, the microcapsule ink was prepared by mixing the GOD/TTF microcapsules ( 3.3 $\mathrm{cm}^{3}$ ) and a saturated TTF methanol solution $\left(1 \mathrm{~cm}^{3}\right)$ with a commercially available carbon ink (ECM-100AF500, Taiyo Ink, $1 \mathrm{~cm}^{3}$ ). The microcapsule ink was printed on the homemade carbon electrode surface by using the screen-printer (LS-150TV, Newlong Seimitsu Kogyo) and then dried at $25^{\circ} \mathrm{C}$ for $30 \mathrm{~min}$. The volume of the micro-
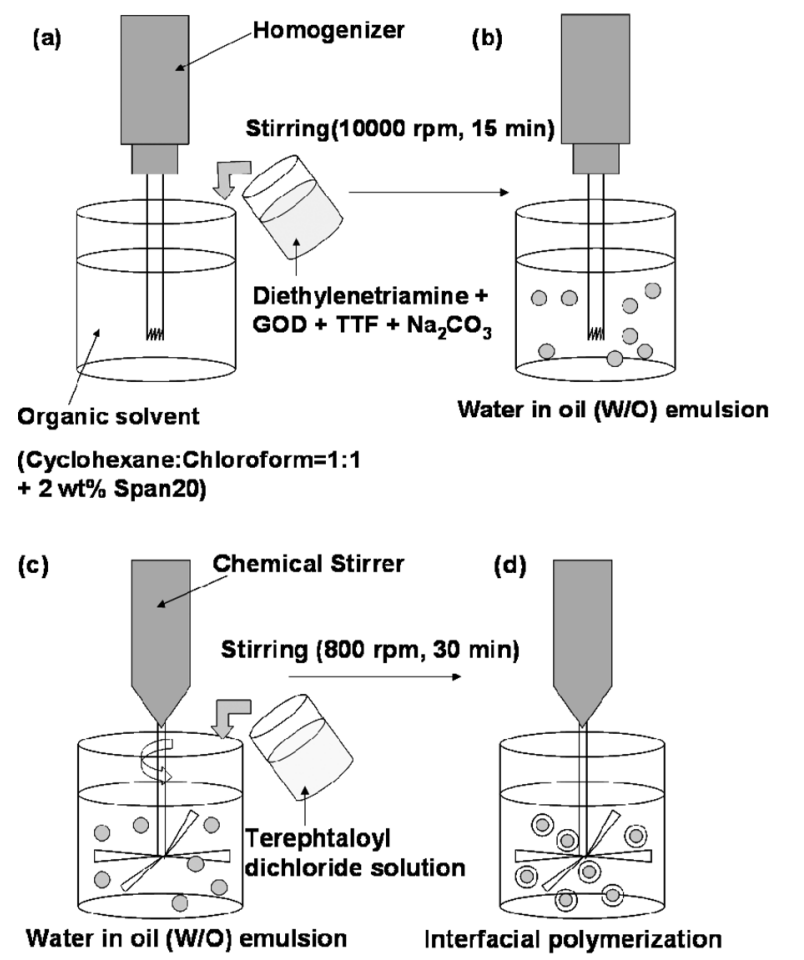

Fig. 1 Schematic illustrations of the preparation methods of the polyamide microcapsules containing GOD and TTF with phosphate buffer solution. capsule ink which was printed on the single carbon electrode surface was about $9 \times 10^{-3} \mathrm{~cm}^{3}$. Theoretical amount of GOD immobilized on the electrode surface was $0.7 \mathrm{U}$. These enzyme electrodes were used for the electrochemical measurements immediately after preparation.

All electrochemical measurements were performed in a $67 \mathrm{mmol} \mathrm{dm}^{-3}$ phosphate buffer solution containing 0.5 mol dm ${ }^{-3}$ sodium sulfate $(\mathrm{pH} 7.4)$ in the presence and absence of glucose. This solution, in which deaeration was not performed, was kept at $25^{\circ} \mathrm{C}$ by a constant-temperature unit. $\mathrm{A} \mathrm{Ag} / \mathrm{AgCl}$ and a coiled platinum wire were used as reference and counter electrodes, respectively. A digital potentiostat (ALS802B, BAS) was used for cyclic voltammetry. The potential of the enzyme electrodes were swept at $5 \mathrm{mV} \mathrm{s}^{-1}$.

\section{Results and Discussion}

A polyamide microcapsule is a small sphere with a porous membrane around it. An enzyme contained in the microcapsule can be isolated from its surroundings. Especially, the microcapsule, prepared in this study, is expected to protect the enzyme from organic substances since the aqueous buffer solution contained in the microcapsule is reduced inhibitory action of the organic substances. On the other hand, the enzyme can selectively react with a particular low-weight-molecular substance which can penetrate the porous membrane. In addition, the polyamide microcapsule has high stability to chemical agents and high mechanical strength. Therefore, the polyamide microcapsule was used for the present study. It is noted that the polymerization reaction does not particularly inhibit the activities of the enzyme in the microcapsule. ${ }^{8)}$

The GOD/TTF microcapsule was prepared by interfacial polymerization method. ${ }^{8)}$ The polyamide membrane is formed at interface of the $\mathrm{W} / \mathrm{O}$ emulsion by the polycondensation reaction, at which DETA in the aqueous solution reacts rapidly with TDC in the organic solvent at water-oil interface (Fig. 1(b)-(d)). Figure 2 shows the photograph of the GOD/TTF microcapsules. The spherical microcapsules were found to be prepared. The size of the microcapsules was distributed from $5 \mu \mathrm{m}$ to $13 \mu \mathrm{m}$. The average diameter of the microcapsules was $7.0 \mu \mathrm{m}$.

To appreciate the function of the GOD/TTF microcapsule as a molecular recognition element, a screen-printed

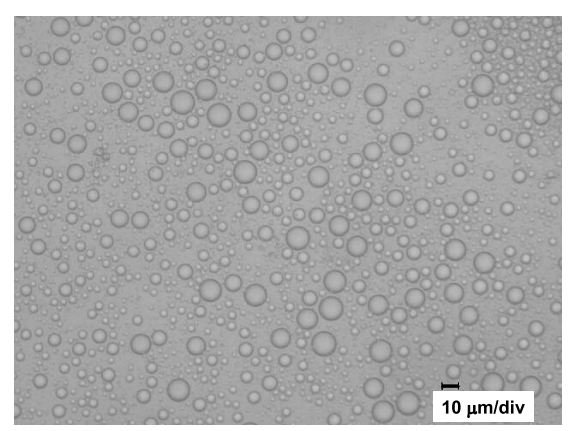

Fig. 2 Photograph of the microcapsules containing glucose GOD and TTF. The average diameter of the microcapsules was $7.0 \mu \mathrm{m}$. 
carbon electrode modified the GOD/TTF microcapsule with the polyion complex film (PIC/GOD/TTF electrode) was prepared, and the electrochemical performance of the PIC/GOD/TTF electrode was evaluated. Polyion complexes are insoluble film formed by the electrostatic interaction between polycations and polyanions. Since alternatively layered polyion complexes are able to entrap various particles, ${ }^{10,11)}$ the polyion complex was here used. Figure 3 shows schematic illustration showing perspective reaction schemes for the GOD/TTF microcapsule with glucose at the carbon electrode surface. GOD is reduced by the reaction with glucose penetrating to the microcapsule membrane. The reduced GOD is oxidized by mediating electron transfer between the enzyme and the carbon electrode with redox reaction of TTF. 12,13$)$

Figure 4 shows cyclic voltammograms of the $\mathrm{PIC} / \mathrm{GOD} / \mathrm{TTF}$ electrode investigated in the $67 \mathrm{mmol} \mathrm{dm}{ }^{-3}$ phosphate buffer solution at $25^{\circ} \mathrm{C}$. The $\mathrm{PIC} / \mathrm{GOD} / \mathrm{TTF}$ electrodes were immersed in the sample solution for 5 min prior to the measurement. In the $35 \mathrm{mmol} \mathrm{dm}^{-3}$ glucose solution, the oxidation current started to flow at $0.15 \mathrm{~V}$ and drastically increased at higher potential than

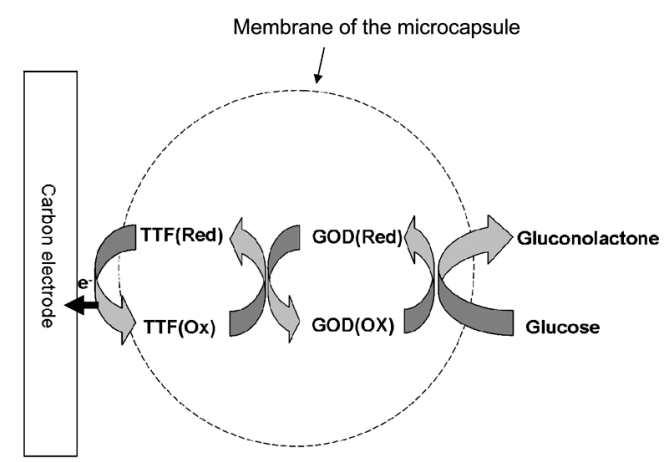

Fig. 3 Schematic illustration showing expected reaction schemes for the GOD/TTF microcapsule with glucose at the carbon electrode surface.

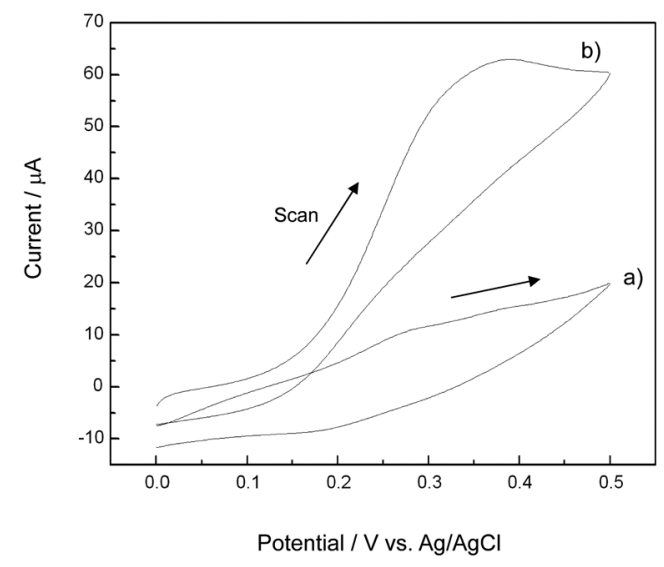

Fig. 4 Cyclic voltammograms of a PIC/GOD/TTF modified screen-printing carbon electrode in $67 \mathrm{mmol} \mathrm{dm}{ }^{-3}$ phosphate buffer solutions containing glucose. The glucose concentrations were a) $0 \mathrm{mmol} \mathrm{dm}^{-3}$ and b) $35 \mathrm{mmol} \mathrm{dm}^{-3}$, respectively. Scan rate was $5 \mathrm{mV} \mathrm{s}^{-1}$.
$0.2 \mathrm{~V}$ in the anodic scan. On the other hand, the drastically increase of the oxidation current was hardly observed at the same potential region in the absence of glucose. These results indicated that the PIC/GOD/TTF electrode is active to oxidize the dissolved glucose which is catalyzed by the entrapped GOD. In addition, the electroactive TTF molecules were found to penetrate the polyamide membrane and to function as a mediator which promotes the electron transfer between the active site of GOD and carbon electrode surface. ${ }^{13)}$ From these results, the GOD/TTF microcapsule was proved to be available for the molecular recognition element of the enzyme ink.

The screen-printed carbon electrode immobilizing the microcapsule enzyme ink (MIC/GOD/TTF electrode) was fabricated. The microcapsule ink was prepared by mixing the carbon ink, the GOD/TTF microcapsule, and saturated TTF methanol solution. The MIC/GOD/TTF electrode surface was black in color due to the carbon. Figure 5 shows the cyclic voltammograms of the $\mathrm{MIC} / \mathrm{GOD} / \mathrm{TTF}$ electrode investigated in the $66.7 \mathrm{mmol}$ $\mathrm{dm}^{-3}$ phosphate buffer solutions containing glucose at $25^{\circ} \mathrm{C}$. The glucose concentrations in the sample solutions were $0,1,2,3,5,7$ and $10 \mathrm{mmol} \mathrm{dm}^{-3}$, respectively. The $\mathrm{MIC} / \mathrm{GOD} / \mathrm{TTF}$ electrodes were immersed in the sample solution for $5 \mathrm{~min}$ prior to the measurements. In the $0 \mathrm{~mol} \mathrm{dm}^{-3}$ glucose (glucose free) solution, the redox couple was observed around $0.4 \mathrm{~V}$ due to the electrochemical redox of TTF. ${ }^{13)}$ This redox response was stable when successive potential cycling. The shape of the voltammogram changed as shown in Fig. 5 in the presence of the glucose. The oxidation current clearly increased with the increase of glucose concentration between 1 to $5 \mathrm{mmol} \mathrm{dm}^{-3}$ at the potential region nobler than $0.4 \mathrm{~V}$. When the higher glucose concentration than $5 \mathrm{mmol} \mathrm{dm}-3$, the oxidation current did not increase at the potential region. The saturation of the oxidation current would be due to the limitation of the enzyme activity of GOD or the TTF concentration contained in the microcapsule. From these results, the MIC/GOD/TTF

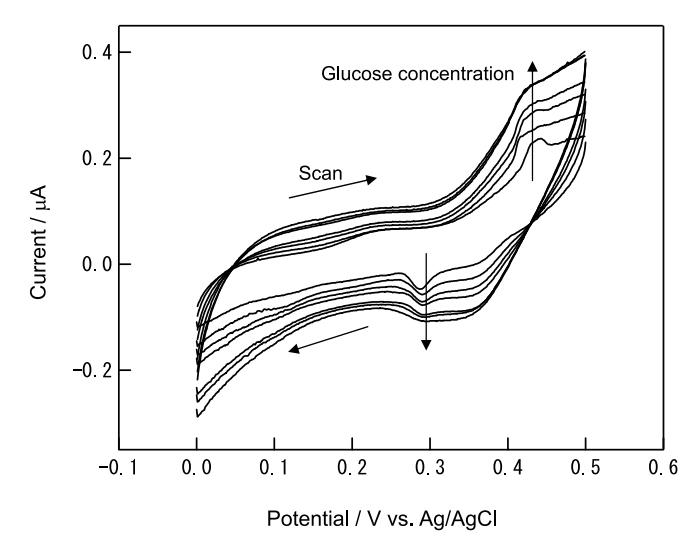

Fig. 5 Cyclic voltammograms of a MIC/GOD/TTF modified screen-printing carbon electrode in $67 \mathrm{mmol} \mathrm{dm}^{-3}$ phosphate buffer solutions containing glucose. The glucose concentrations were $0,1,2,3,5,7$ and $10 \mathrm{mmol} \mathrm{dm}^{-3}$, respectively. Scan rate was $5 \mathrm{mV} \mathrm{s}^{-1}$. 
electrode has potential for the application to biosensors. The increase of the oxidation current of the $\mathrm{MIC} / \mathrm{GOD} / \mathrm{TTF}$ electrode did not clearly appear in comparison with that of the $\mathrm{PIC} / \mathrm{GOD} / \mathrm{TTF}$ electrode. It is likely that the reduced TTF molecules, which generated by the enzyme reaction in the microcapsule, eluted in the buffer solution. The elution will be able to depress by additional coating of a film on the PIC/GOD/TTF electrode by using a screen printing. In addition, in Fig. 5, the reduction current was also increased with the increase of glucose concentration around $0.35 \mathrm{~V}$, and the reduction current began to increase with the increase of glucose concentration at $0.1 \mathrm{~V}$ at cathodic scan. In the present study, dissolved oxygen which might react with the reduced GOD to some extent was not removed by deaeration. Hydrogen peroxide is generated if the dissolved oxygen reacts with the reduced GOD. The reduced TTF molecules which exist near the electrode surface could partly be oxidized by hydrogen peroxide. The increase of the reduction current, mentioned above, might be due to the oxidized TTF molecules. Investigation of the cathodic current increases is in progress and will be reported elsewhere.

\section{Conclusion}

A polyamide microcapsule containing glucose oxidase and tetrathiafulvalene was prepared for the fabrication to the screen-printed enzyme electrode. The microcapsule was proved to be available for the molecular recognition element of the enzyme ink. The microencapsula- tion technique is expected to apply for not only glucose oxidase but also many other enzymes.

\section{References}

1) J. Wang, P. V. A. Pamidi, and D. S. Park, Anal. Chem., 68, 2705 (1996).

2) A. L. Hart, W. A. Collier, and D. Janssen, Biosens. Bioelectron., 12, 645 (1997).

3) M. P. O'Halloran, M. Pravda, and G. G. Guilbault, Talanta, 55, 605 (2001).

4) K. C. Honeychurch, J. P. Hart, and D. C. Cowell, Anal, Chim, Acta, 431, 89 (2001).

5) Q. Gao, W. Wang, Y. Ma, and X. Yang, Talanta, 62, 477 (2004).

6) E. Turkusic, J. Kalcher, and E. Kahrovic, Talanta, 65, 559 (2005).

7) M. Tudorache and C. Bala, Anal. Bioanal. Chem., 388, 565 (2007).

8) K. Hoshino, N. Muramatsu, and T. Kondo, J. Microencapsulation, 6, 205 (1984).

9) R. V. Parthasarathy and C. R. Martin, Nature, 369, 298 (1994).

10) I. Shitanda, K. Takada, Y. Sakai, and T. Tatsuma, Anal. Chim. Acta, 530, 191 (2005).

11) S. Yabuki, F. Mizutani, and Y. Hirata, J. Electroanal. Chem., 468, 117 (1999).

12) I. Taniguchi, D. Tabata, M. Kishikawa, M. Otani, K. Nishiyama, M. Tominaga, and T. Sotomura, ITE Lett., 8, 133 (2007).

13) S. Komaba, T. Mitsuhashi, and S. Shiraishi, Electrochemistry, 76, 55 (2008). 